\title{
MODEL TO DETERMINE THE INVESTMENT PRIORITY FOR TELECONTROLLED FACILITIES IN SANITARY INDUSTRY IN CHILE TO ADAPT TO CLIMATE CHANGE
}

\author{
Claudio J. Macuada ${ }^{1}$, Astrid M. Oddershede ${ }^{2}$, Luis E. Quezada ${ }^{3}$, Pedro I. Palominos ${ }^{4}$ \\ 1,2,3,4 Industrial Engineering Department \\ University of Santiago of Chile, Santiago, Chile \\ claudio.macuadalusach.cl \\ astrid.oddershede@usach.cl \\ luis.quezada@usach.cl \\ pedro.palominos@usach.cl
}

\begin{abstract}
This study proposes a methodology to support decision making when determining the order of investment of telecontrolled facilities in the health industry, contemplating the impacts of climate change. The sanitary industry has been constantly concern in providing greater resilience to the supply of drinking water in face of the effects related to climate change by improving its processes; augmenting the coverage, continuity and quality of drinking water and treatment of sewage water in all Chilean cities. This has had a very favorable impact on the population health and has allowed for a great development of tourism and the agrofood industry; all this, with low rates compared to other countries. The water industry is aware that it is necessary to keep up the speed of investments to maintain service levels and to deal in a timely and effective manner with events that involve customers, due to environment situations, climate change and also the operational and human contingencies of companies in the sector. In this sense, the water industry is adopting new technologies for its processes, with the purpose of making them a factor of service improvement. Currently, the Chilean Sanitary Industry is concerned about the degree of automation and infrastructure requirements, since they are the main critical factors for planning future investments. This document emphasizes the development of a decision model applying the Analytical Hierarchy Process (AHP), to define the order of medium term investments for remote controlled facilities.
\end{abstract}

Keywords: Degree of Automation, Telecontrolled Facilities, Investment Plan, Sanitary Industry, Climate Change, AHP.

\section{Introduction}

As pointed out by Bates et al. (2008), climate change affects global water resources in multiple ways, with spatial-temporal patterns, feedback effects and interactions between physical and human processes. These effects imply challenges to the sustainable management of water resources, due to the high climate variability in many regions of the world. The latter affects the availability, quality and quantity of water to meet basic human needs, thus threatening the essential human right to water and sanitation for millions of 
people. Under this context, Chile illustrates some progress and presents pending challenges in addressing climate change through water as evidenced in the Adaptation Plans (Chilean Ministry of Environment, 2014), which recognize the need for institutional development in all planning, policy and information systems, along with infrastructure. The development plan generated by Chile, tends to recognize the water-related impacts of climate change and, in some cases, the importance of water management for economic development. In particular, "Chile's Agenda 2030" outlines a reform program and action that includes laws, plans, programs and other initiatives to achieve Sustainable Development Goal 6 (SDA 6): Universal access to sustainable water and sanitation services, the existing impacts of climate change, including in terms of water scarcity (Chile Agenda 2030, n.d.). While the National Adaptation Plan, recognizes the impacts related to water, especially on farmers in dry land areas through the use and management of water resources; and the role of the sanitary industry in ensuring water supply. For the latter, it emphasizes the need to incorporate technology that allows for the anticipation of catastrophic events, related to information on water resources and climate data that facilitate timely decision making and account for the need for further adaptation measures. However, in the water industry there are no guidelines to identify the current technological level, nor the required level, and even less the priority technological systems to generate an investment program in infrastructure that will gradually reduce the impacts of climate change on the water industry.

\section{Literature Review}

In relation to the background that has provided a context for this study, we can mention what Bates et al. (2008), refers to, as freshwater resources are vulnerable and can be seriously affected by climate change, with various consequences for human societies and ecosystems, highlighting that a) The warming observed over several decades has been linked to changes experienced by the hydrological cycle on a large scale; b) The increasing intensity and variability of precipitation is projected to increase the risk of floods and droughts in many areas; c) Water reserves stored in glaciers and snow cover are projected to decrease during this century; d) Increases in water temperature and the variation of extreme events, including floods and droughts, are projected to affect water quality and exacerbate water pollution from multiple causes; e) Changes in water quantity and quality due to climate change would affect the availability, stability, accessibility and use of food; f) Climate change affects the function and use of existing water infrastructure - particularly hydropower, structural flood protection, drainage, and irrigation systems - as well as water management practices; g) Current water management practices may not be robust enough to counteract the effects of climate change; h) Adaptation options for ensuring water supply under normal conditions and in the event of drought require integrated strategies that address both demand and supply; and finally i) There are information gaps both in terms of observations and research needs in relation to climate change and water. Furthermore, at the local level, the National Plan for Adaptation to Climate Change (Ministry of the Environment, 2014) states that it is necessary to make investments in infrastructure that will make it possible to adopt solutions that will meet society's needs in a context of uncertainty in the face of weather events, and that the State of Chile must consider an appropriate level of investment, especially in the development of infrastructure, incorporating technology to strengthen the water sector and safeguard the impact on productivity, with agriculture expected to be affected by changes in temperature and rainfall. Macuada et al, (2021) proposes a method to determine the most appropriate degree

International Symposium on the Analytic Hierarchy Process
DEC. 3 - DEC. 6,2020 
ISAHP Article: A Style Guide for Paper Proposals To Be Submitted to the International Symposium on the Analytic Hierarchy Process 2020, Web Conference.

of automation to face climate change for a plant within the health industry through an AHP model.

\section{Hypotheses/Objectives}

This study is an extension of the work done by Macuada et al. (2021). The study refers to the development of a decision model to prioritize investment projects associated with various water storage and distribution and wastewater collection plants, according to their required degree of automation.

Therefore, the study intends to design a procedure that involves tangible variables through the benefit-cost analysis $(\mathrm{B} / \mathrm{C})$ and intangible variables through an AHP model in order to obtain a weighted prioritization between both types of variables.

\section{Research Design/Methodology}

The study consists of four main phases: The first one consists of characterizing the remote controlled facilities for investment purposes according to the result that delivers the $\mathrm{B} / \mathrm{C}$ index for each of the installations in a decreasing way.

The second phase tries to define the significant criteria considering relevant variables, such as, treatment capacity, distance between facilities. To do this, a panel of experts in the health sector working in a water company (directors, managers, project engineers and engineers of the operational control center) must be composed.

The third phase, a hierarchy structure is generated to represent the problem situation incorporating the main factors and criteria. Applying the AHP method (Saaty, 1997; Mu \& Pereyra-Rojas, 2020) the team of experts evaluates which criteria are most relevant and estimates the result based on a multi-criteria approach to obtain the most priority investment facilities.

In the fourth phase, a weighting is made between the results considering the economic ratios, that is, tangible variables such as the $\mathrm{B} / \mathrm{C}$ index and other variables, through the AHP method, achieving a unified weighting for the different remote controlled installations.

\section{Data/Model Analysis}

Using the $\mathrm{B} / \mathrm{C}$ index for each of the installations according to their most suitable degree of automation, the following order is obtained from highest to lowest ratio: 1) EERR = 1.99; 2) $\mathrm{VES}=1.87$; 3) $\mathrm{PEAP}=1.81$; 4) $\mathrm{PBP}=1.61$; $)$ PTAN $=1.59$; 6) $\mathrm{PEAS}=1.50$; 7) $\mathrm{SDC}$ $=1.05 ; 8) \mathrm{SDF}=1.04$. We can see that $\mathrm{B} / \mathrm{C}$ in all cases is greater than 1 , which indicates that the benefits are greater than the costs.

Then, to consider the relevant variables, it is proposed to represent the situation of the problem by means of a hierarchical model in order to determine the priority of investment for the remote controlled installations in terms of criteria, being evaluated by a group of experts. A two-level hierarchy is modeled that includes the decision factors that contribute to the achievement of the objective. These factors are based on the comparative evaluation between the different criteria and determine the investments to guarantee the continuity of the service.

The levels of the hierarchical structure are as follows:

- Level 0: It is the main objective, which is the most priority remote control installation to be invested according to its most suitable degree of automation? 
ISAHP Article: A Style Guide for Paper Proposals To Be Submitted to the International Symposium on the Analytic Hierarchy Process 2020, Web Conference.

- Level 1: It includes the criteria that will help to determine the priority of investment for the telecontrolled facilities.

- Level 2: Includes all telecontrolled facilities.

While the criteria that were considered to meet the objective are:

- Capacity: Refers to the amount of water treated in the plants during a certain period of time.

- Distance: Refers to the physical distance from the facility to the OCC.

- Redundancy: Refers to having additional elements that guarantee its operation if one of its components fails.

- Obsolescence: Refers to the insufficient performance of its functions in comparison with the new machines, equipment and technologies introduced in the market.

- Customer Impact (Affectation): Number of customers who are impacted by the service.

The results of the AHP model show that the most relevant criterion is Capacity, which determines the result of the highest priority facilities from the highest to the lowest weighting according to the following: 1) EERR $=22.1 \%$; 2) PEAP $=21.0 \%$; 3) VES $=$ $13.8 \%$; 4) $\mathrm{PBP}=13.4 \%$; 5) $\mathrm{PEAS}=13.2 \%$; 6) $\mathrm{SDC}=7.2 \%$; 7) $\mathrm{SDF}=5.9 \%$; 8) $\mathrm{PTAN}=$ $3.2 \%$.

The results of the $\mathrm{B} / \mathrm{C}$ analysis and the AHP model are then normalized, finally obtaining the following order of priority: 1) $\mathrm{EERR}=0.22$; 2) $\mathrm{PEAP}=0.21$; 3) $\mathrm{VES}=0.14$; 4) $\mathrm{PBP}$ $=0.13 ; 5) \mathrm{PEAS}=0.13 ; 6) \mathrm{SDC}=0.07 ; 7) \mathrm{SDF}=0.06 ; 8) \mathrm{PTAN}=0.03$.

The steps developed to obtain this result are shown in Figure 1.

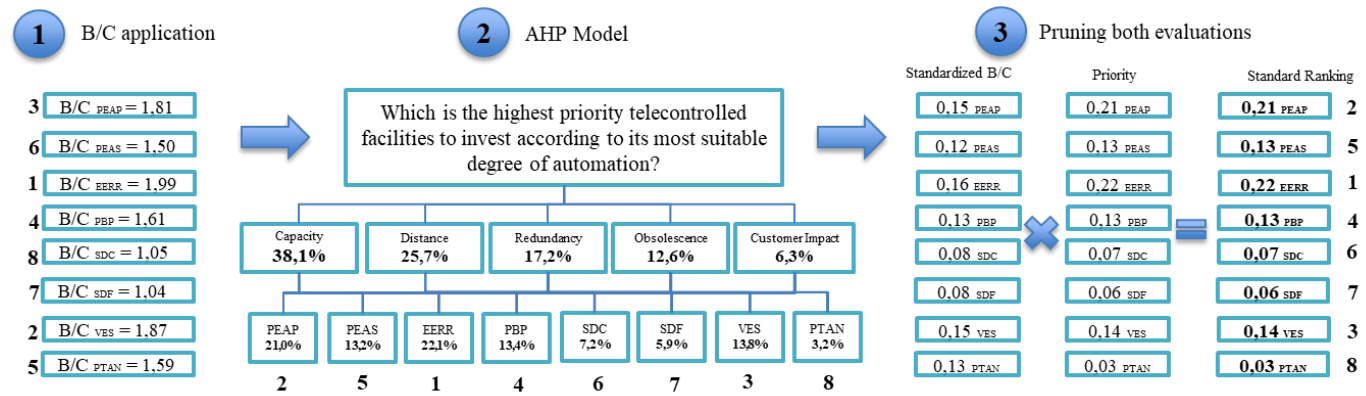

Fig. 1. Weighting B/C Analysis and AHP Model

This result is consistent with the organization's concern for adapting to climate change by ensuring continuity of drinking water service in a timely manner and thus avoiding affecting customers, loss of reputation and impact on the city.

\section{Limitations}

The proposed model assumes that there is no interrelationship between the variables. 
ISAHP Article: A Style Guide for Paper Proposals To Be Submitted to the International Symposium on the Analytic Hierarchy Process 2020, Web Conference.

\section{Conclusions}

With this work it was possible to conclude that it is possible to use AHP to prioritize investment projects for facility automation in the health industry.

Through a real case study of prioritization of variables that affect the investment of remote controlled installations in a Chilean sanitary company, the methodology provided explicit recommendations to the company's management, which considered the solution appropriate, since it allowed a detailed understanding of each of the priority requirements and identified the infrastructure to be improved. On the other hand, the results of this study can serve as a guide for other industrial process operating companies that need to raise their technological level and prioritize investments to ensure continuity, quality and continuity of service and adapt to climate change.

The study gives a reference of the criteria that can be considered to define a standard in the health industry regarding the necessary investments within a National Action Plan against Climate Change.

\section{Key References}

Bates, B. C., Kundzewicz, Z. W., Wu, S. y Palutikof, J. P. (eds.). (2008). Climate Change and Water. Documento Técnico del Grupo Intergubernamental sobre Cambio Climático $(I P C C)$. Ginebra, IPCC Secretariat. www.ipcc.ch/publication/climate-change-and-water$2 /$.

ChileAgenda2030. s.f. Sobre la Agenda de Desarrollo Sostenible. www.chileagenda2030.gob.cl/agenda-2030/sobre-la-agenda (en español)

Macuada C.J., Oddershede A.M., Quezada L.E., Palominos P.I. (2021) Methodological Proposal to Define the Degree of Automation in the Sanitary Industry in Chile to Adapt to Climate Change. Advances in Intelligent Systems and Computing, vol 1243. Springer, Cham. https://doi.org/10.1007/978-3-030-53651-0_24

Ministerio de Medio Ambiente de Chile. (2014). Plan Nacional de Adaptación al Cambio Climático [National Plan for Climate Change Adaptation]. Government of Chile. www4.unfccc.int/sites/NAPC/Documents/Parties/Chile\%20NAP\%20including\%20sector al\%20plans\%20Spanish.pdf

Mu, E., \& Pereyra-Rojas, M. (2020). Toma de decisiones prácticas: Una introducción al Proceso Jerárquico Analítico (AHP) usando Super Decisions v2 y v3. Milagros PereyraRojas.

Saaty, T.L. (1997). Toma de Decisiones Para Líderes. El Proceso Analítico Jerárquico. La Toma de Decisiones en un Mundo Complejo, RWS Publications, USA. 